\title{
CHEMISTRY
}

\section{CONTINUOUS METHOD FOR OBTAINING OF NOVOLAC OLIGOMER AND MIXED COPOLYMER IN MELT}

\author{
${ }^{1}$ Zaza Molodinashvil, doctor of chemistry \\ ${ }^{2}$ Nikoloz Zazashvili, academic doctor \\ ${ }^{3}$ Michaeli Tchichakua, academic doctor \\ ${ }^{4}$ Marina Chikaidze, academic doctor \\ ${ }^{5}$ Dali Razmadze master degree
}

\begin{abstract}
Georgia, Tbilisi,
${ }^{1}$ Ivane Javakhishvili Tbilisi State University, Petre Melikishvili Institute of Physical and Organic Chemistry, Laboratory of petrochemistry and LTD "Biotecsi": Senior Research fellow, Expert in thermoplastic materials, technologies;

${ }^{2}$ LTD "Biotecsi" end Bio-rational Technological Research Center (BrTRC), Leading Researcher;

${ }^{3}$ LTD "Biotecsi" and LTD "Biochemsynthesis", Leading Researcher;

${ }^{4}$ LTD "Biotecsi” end Bio-rational Technological Research Center (BrTRC), Leading Researcher;

${ }^{5}$ Bio-rational Technological Research Center (BrTRC), Head of the Testing Laboratory.
\end{abstract}

DOI: https://doi.org/10.31435/rsglobal_ws/30082018/6067

\section{ARTICLE INFO}

Received: 27 July 2018

Accepted: 15 August 2018

Published: 30 August 2018

\section{KEYWORDS}

novolac, oligomer, copolymers, polycondensation, phenol, card-type bisphenols, paraform.

\begin{abstract}
A new continuous method for production of novolac-type oligomers by interaction of phenol with paraform in the melt in the presence of acid catalyst was developed. To establish the optimal conditions of the reaction, some kinetic regularities of the process were investigated. It is shown that the reaction is of the second order. The optimal conditions for formation of the oligomer are the following: temperature $-100-120^{\circ} \mathrm{C}$; duration of the reaction - $10 \mathrm{~min}$; phenolic component: formaldehyde molar ratio $-1.15: 10$; amount of the catalyst $-1 \%$ in relation to the phenolic component. Also, to enhance the heat resistance of the polymers, complex polymers with statistical arrangement of monomers in the macromolecule were synthesized by simultaneous condensation of phenol and card-type bisphenols in the melt. The softening temperature of co-oligomers was increased from $70{ }^{\circ} \mathrm{C}$ to $90-180{ }^{\circ} \mathrm{C}$.
\end{abstract}

Citation: Zaza Molodinashvil, Nikoloz Zazashvili, Michaeli Tchichakua, Marina Chikaidze, Dali Razmadze. (2018) Continuous Method for Obtaining of Novolac Oligomer and Mixed Copolymer in Melt. World Science. 8(36), Vol.2. doi: 10.31435/rsglobal_ws/30082018/6067

Copyright: (C) 2018 Zaza Molodinashvil, Nikoloz Zazashvili, Michaeli Tchichakua, Marina Chikaidze, Dali Razmadze. This is an open-access article distributed under the terms of the Creative Commons Attribution License (CC BY). The use, distribution or reproduction in other forums is permitted, provided the original author(s) or licensor are credited and that the original publication in this journal is cited, in accordance with accepted academic practice. No use, distribution or reproduction is permitted which does not comply with these terms.

Introduction. Since the beginning of the XX century, phenolic resins belonging to the class of thermoreactive polymers have found wide application in almost all fields of national economy due to their valuable properties. They were produced synthetically by polycondensation reaction of phenol with formaldehyde. Cresols, xylenols, multiatomic phenols, alkylphenols, multinuclear compounds, for example bisphenols and others were used as phenolic raw materials alongside with phenol [1-5]. 
Availability of raw materials base, simplicity of production technology and relatively low cost of formaldehyde polymers together with their high exploitation properties determine their wide usage in production of materials that have ability to work in extreme (high temperature and specific load) conditions [6-10].

Phenol-formaldehyde polymers are widely used in the form of polymeric compositions in which the main role is played by excipients. The excipients give a possibility to obtain plastics with wide range of properties. At the same time this is a way to decrease the polymer proportion in the polymeric composition significantly and to reduce the price of polymeric materials [11-12].

Even in conditions of steady development of production of foam plastics (one of the oldest polymeric materials) have not lost their significance and it is possible that they will be developed in future and their production will be increased. It is known that strong stimulus to increase their production was given by a shortage of natural raw materials as well as the necessity to replace natural materials by their synthetic analogues [13-15].

Experimental Section. Novolac is usually produced by the reaction between phenol and formaldehyde in water solution, in an acid medium. This process is periodical. Hence it was of interest to develop a continuous method of production of novolac, because, in this case, we could use novolac immediately, without performing additional procedures. Besides, we would eliminate the necessity in processing of rinsing water, containing phenol and formaldehyde that did not enter into the reaction, and polluting the environment. Processing of rinsing water for removal of phenol, formaldehyde and the acid from it is a serious problem at all operating plants. Another serious problem is removal of water from obtained novolac, its drying, which is associated with power costs as well [16].

A continuous method for obtaining of novolac by interaction of phenol and formaldehyde in melt is developed. For the purpose of development of the continuous method a paraform was used instead of water solution of formaldehyde. Reaction was carried out in melt, by heating of paraform and phenol in the presence of acid, catalyst (Fig.1). Molar ratio of phenol and formaldehyde was 1,15:1. As a catalyst was used hydrochloric acid (against $1 \%$ of phenol). Under heating paraform undergoes depolymerazation, and the obtained formaldehyde immediately reacts with phenol. The reaction of dipolymerization of paraform can be presented by the following scheme:

$$
-\left(\mathrm{CH}_{2} \mathrm{O}_{n}\right) \rightarrow\left(\mathrm{CH}_{2} \mathrm{O}\right)_{n-1}+\mathrm{CH}_{2} \mathrm{O} \rightarrow\left(\mathrm{CH}_{2} \mathrm{O}\right)_{n-2}+\mathrm{CH}_{2} \mathrm{O} \rightarrow-\left(\mathrm{CH}_{2} \mathrm{O}\right)_{n-3}+\mathrm{CH}_{2} \mathrm{O}
$$

and so on.

When the obtained formaldehyde reacts with phenol sequential and parallel reactions of addition and condensation take place [17]. By condensation of formaldehyde with phenol in acid area phenolalcohols are formed, and after reaction with phenol they are transformed in dioxyphenylmethane (Fig.2). The reaction is carried out according to the following scheme:

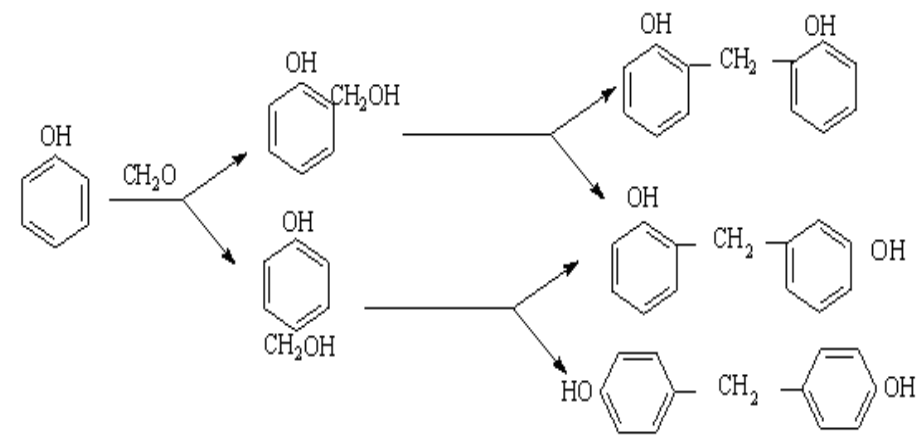

The obtained dioxyphenylmethane reacts with formaldehyde or phenolalcohols. Oligomer is obtained, in which the phenolic rings are connected with each other with methylene bridges. Further growth of chain happens as a result of addition and condensation reactions. However, the rate of the condensation reaction is much greater than that of the addition reaction and as a result the obtained oligomer does not contain methylol groups which is confirmed by IR spectral analysis [18-19].

In general, the process of condensation in acidic area can be represented by the following scheme (Fig.3):

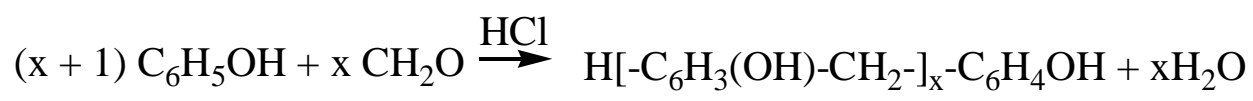

where $\mathrm{x}=4-8$ 
As there was no information in literature about the character of the course of the reaction between phenol and paraform in the melt, and as well to establish optimal conditions of the synthesis of the novolactype oligomer in the melt, we studied some kinetic regularities of oligomer formation [20].

Results and Discussion. For production of the novolac oligomer, the reaction in the melt proceeded over the temperature range from 40 to $120{ }^{\circ} \mathrm{C}$. The phenol:formaldehyde molar ratio was 1.15:1.0. Hydrochloric acid was used as a catalyst ( $1 \%$ of the phenolic component).

The course of the reaction was controlled by changes in the amount of formaldehyde in the reaction mixture. Changes in the amount of formaldehyde in the reaction area with interaction with phenol at different temperature are presented in Table I. When the temperature increased from 40 to $120{ }^{\circ} \mathrm{C}$, after 10 seconds the amount of free formaldehyde in the reaction area decreased as follows: $95.40>92.76>84.05>76.30>70.23$; after $1 \mathrm{~min}: 75.85>58.99>45.00>34.27>28.38$; after $10 \mathrm{~min}:$ $55.85>27.70>>21.24>15.45>11,69$. When the process was prolonged at $40^{\circ} \mathrm{C}$, after $10 \mathrm{~s}, 1 \mathrm{~min}$ and $10 \mathrm{~min}$, the amount of formaldehyde decreased as follows: $95.40>75.85>55.85$; at $60^{\circ} \mathrm{C}$ : $92.76>58.99>27,70$; at $80^{\circ} \mathrm{C}: 84.05>45.00>21.24$; at $100^{\circ} \mathrm{C}: 76.30>34.27>15.45$; at $120^{\circ} \mathrm{C}: 70.23>$ $>28.38>11,69 \%$ :

Table 1. Chenges in the order of formaldehyde transformation with the reaction between phenol and paraform in the melt with the reaction proceeding over the temperature range from 40 to $120{ }^{\circ} \mathrm{C}^{*}$

\begin{tabular}{|c|c|c|c|c|c|}
\hline \multirow{2}{*}{$\begin{array}{c}\text { Duration of } \\
\text { the reaction, s }\end{array}$} & \multicolumn{5}{|c|}{ Amount of formaldehyde that did not enter into the reaction, \% } \\
\cline { 2 - 6 } & $40^{\circ} \mathrm{C}$ & $60^{\circ} \mathrm{C}$ & $80^{\circ} \mathrm{C}$ & $100^{\circ} \mathrm{C}$ & $120^{\circ} \mathrm{C}$ \\
\hline 10 & 95.40 & 92.76 & 84.05 & 76.30 & 70.23 \\
\hline 20 & 90.55 & 81.35 & 70.96 & 61.41 & 54.22 \\
\hline 30 & 86.30 & 74.16 & 62.14 & 51.30 & 44.11 \\
\hline 45 & 80.90 & 66.30 & 53.32 & 41.02 & 34.56 \\
\hline 60 & 75.85 & 58.99 & 45.00 & 34.27 & 28.38 \\
\hline 90 & 67.98 & 48.88 & 35.17 & 25.85 & 20.79 \\
\hline 120 & 61.24 & 41.80 & 29.39 & 20.79 & 16.41 \\
\hline 240 & 57.31 & 35.51 & 26.07 & 18.54 & 16.13 \\
\hline 600 & 55.85 & 27.70 & 21.24 & 15.45 & 11.69 \\
\hline
\end{tabular}

* Molar ratio phenol:formaldehyde is 1.15:1.0

The order of polymerization of the novolac oligomer formed in the melt is 7-8. As is seen, the amount of formaldehyde that did not enter into the reaction decreases with the increasing duration of the process, though the intensity of decreasing is higher at the initial stage. For instance, when the reaction proceeded at $40{ }^{\circ} \mathrm{C}$, after $10 \mathrm{~s}$ the amount of formaldehyde that did not enter into the reaction was $95.40 \%$, after $1 \mathrm{~min}-75.85 \%$; after $2 \mathrm{~min}-61.24 \%$; after $10 \mathrm{~min}-55.85 \%$. At $60^{\circ} \mathrm{C}$ the amount of free formaldehyde decreased as follows: $92.7>58.99>41.80>27.70$, respectively; at $80^{\circ} \mathrm{C}-$ $84.05>45.00>29.39>21.24$, respectively; at $100^{\circ} \mathrm{C}-76.30>34.27>20.79>15,45$, respectively; at $120^{\circ} \mathrm{C}$ $-70.23>28.38>16.41>11,69 \%$, respectively.

The IR spectroscopic analyses showed that, at the first stage of the reaction phenolic alcohols were formed, and then they transformed into dioxidiphenylmethane and oligomers.

To control the reaction, we took samples in certain intervals and measured the amount of formaldehyde that did not enter into the reaction.

Kinetic curves of the reaction of phenol with formaldehyde at different temperature are shown on Figure (1):

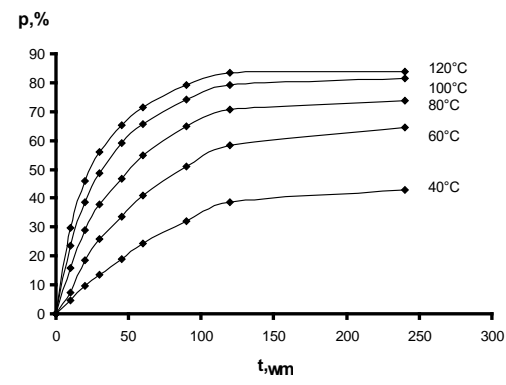

Fig. 1. Kinetic curves of the reaction of phenol with formaldehyde in the presence of a catalyst*at different temperature.

$P$-transformation order; $t$-duration of the reaction; *catalyst $-1 \% \mathrm{HCl}$ in relation to phenol. 
The investigation showed that in the temperature range from 40 to $120{ }^{\circ} \mathrm{C}$, the rate constants of the reaction retain their values calculated by the second-order equation. These data are given in Table II:

Table 2. Some kinetic parameters of the reaction of phenol with formaldehyde over the temperature range from 40 to $120{ }^{\circ} \mathrm{C}$; molar ratio phenol:formaldehyde is $1.15: 1.0$

\begin{tabular}{|c|c|c|c|c|c|}
\hline \multirow{2}{*}{$\begin{array}{c}\text { Duration of } \\
\text { the reaction, } \mathrm{s}\end{array}$} & \multicolumn{5}{|c|}{ Reaction rate constant $\mathrm{K}, 10^{-3} \cdot \mathrm{mol}^{-1} \mathrm{~s}^{-1}$} \\
\hline & $40^{\circ} \mathrm{C}$ & $60^{\circ} \mathrm{C}$ & $80^{\circ} \mathrm{C}$ & $100^{\circ} \mathrm{C}$ & $120^{\circ} \mathrm{C}$ \\
\hline 10 & 0.27 & 0.43 & 0.94 & 1.74 & 2.38 \\
\hline 20 & 0.29 & 0.65 & 1.14 & 1.76 & 2.37 \\
\hline 30 & 0.29 & 0.65 & 1.14 & 1.77 & 2.37 \\
\hline 45 & 0.29 & 0.65 & 1.09 & 1.79 & 2.36 \\
\hline 60 & 0.29 & 0.65 & 1.14 & 1.79 & 2.36 \\
\hline 90 & 0.29 & 0.65 & 1.15 & 1.79 & 2.37 \\
\hline 120 & 0.29 & 0.65 & 1.12 & 1.78 & 2.38 \\
\hline 240 & 0.17 & 0.42 & 0.66 & 1.02 & 1.16 \\
\hline 600 & 0.07 & 0.24 & 0.34 & 0.51 & 0.70 \\
\hline 1800 & - & 0.15 & 0.18 & 0.20 & 0.43 \\
\hline
\end{tabular}

Activation energy $\mathrm{E}=11.4 \mathrm{kcal} / \mathrm{mol}$

Probability factor, A=1.064 1/mol.s

The linear dependence of the logarithm of the reaction on the reversed absolute temperature and that of $1 / \mathrm{a}-\mathrm{x}$ on the reaction duration also point to the second order of the reaction. The activation energy of the reaction was equal to $11.4 \mathrm{kcal} / \mathrm{mol}$ (Figs. 2 and 3):

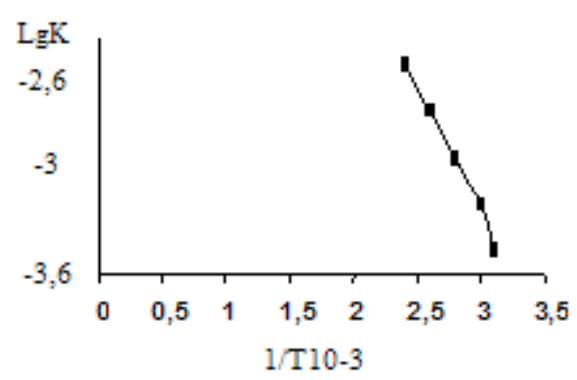

Fig. 2. The dependence of $\operatorname{lgK}$ on the reversed absolute temperature during polycondensation of phenol with paraform at $40-120{ }^{\circ} \mathrm{C}$ in the presence of a catalyst ( $1 \% \mathrm{HCl}$ in relation to phenol)

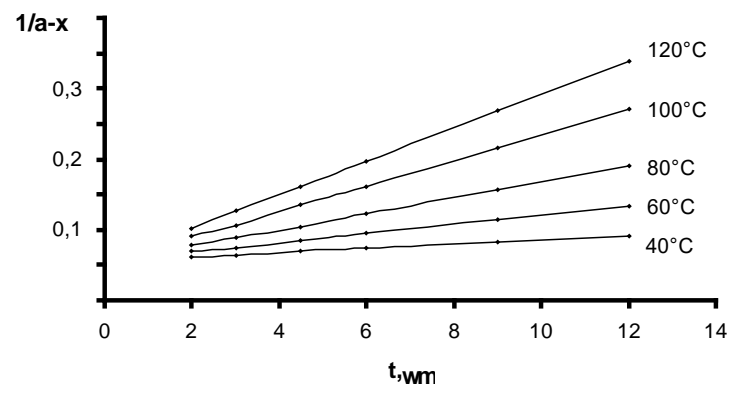

Fig. 3. The dependence of 1/a-x on the duration of polycondensation of phenol with paraform at different temperatures in the presence of a catalyst (1\% HCl in relation to phenol) $a$-initial amount of formaldehyde; $x$-transformation order of formaldehyde

From the kinetic curves of the reaction of phenol with paraform and the data of Table I it is obvious that both the temperature and the reaction duration have an impact on the course of the reaction.

From the data given in Table III, it can be seen that the reaction rate increases with the increasing of temperature, though it decreases significantly with the increasing duration of the reaction. When the duration of the reaction increased from 10 to 600 seconds at constant temperature, 
e.g. $40{ }^{0} \mathrm{C}$, the reaction rate decreased from 0.46 to $0.07 \mathrm{~g} / \mathrm{s}$, while at $120{ }^{\circ} \mathrm{C}$ the transformation order reached a high value after $120 \mathrm{~s}$ (Table 1 ).

When the temperature increased from 40 to $120{ }^{\circ} \mathrm{C}$, the reaction rate constant increased from 0.29 to $2.38 \cdot 10^{-3} 1 \cdot \mathrm{mol} \cdot \mathrm{s}^{-1}$. When the reaction proceeds at higher temperature, a major portion of paraform leaves the reaction area. Hence the maximum temperature of the reaction must not be higher than $120^{\circ} \mathrm{C}$.

Table 3. Changes in the reaction rate depending on the temperature and the reaction duration

\begin{tabular}{|c|c|c|c|c|c|}
\hline \multirow{2}{*}{$\begin{array}{c}\text { Duration of } \\
\text { the reaction, } \mathrm{s}\end{array}$} & $40^{\circ} \mathrm{C}$ & $60^{\circ} \mathrm{C}$ & $80^{\circ} \mathrm{C}$ & $100^{\circ} \mathrm{C}$ & $120^{\circ} \mathrm{C}$ \\
\hline 10 & 0.46 & 0.72 & 1.59 & 2.37 & 2.97 \\
\hline 20 & 0.47 & 0.93 & 1.45 & 1.92 & 2.28 \\
\hline 30 & 0.456 & 0.86 & 1.26 & 1.62 & 1.66 \\
\hline 45 & 0.424 & 0.74 & 1.03 & 1.31 & 1.45 \\
\hline 60 & 0.40 & 0.68 & 0.91 & 1.09 & 1.19 \\
\hline 90 & 3.33 & 0.56 & 0.72 & 0.82 & 0.88 \\
\hline 120 & 0.32 & 0.48 & 0.58 & 0.66 & 0.69 \\
\hline 240 & 0.17 & 0.26 & 0.30 & 0.33 & 0.34 \\
\hline 600 & 0.07 & 0.12 & 0.13 & 0.14 & 0.14 \\
\hline 1800 & - & 0.04 & 0.04 & 0.05 & 0.05 \\
\hline
\end{tabular}

Therefore, the temperature range from 40 to $120{ }^{\circ} \mathrm{C}$ is optimal for the reaction in the melt. At higher temperature, intense depolymerization of paraform takes place and the released formaldehyde has no chance to react with phenol and is lost. The optimal duration of the reaction is 10 minutes.

To enhance the heat resistance of phenol-formaldehyde polymers, we synthesized complex copolymers by simultaneous polycondensation of phenol and card-type bisphenols, which contained phthalide, cyclohexane, norbornane, indane, naphthene and adamant groups [21-22]. When the molar ratio of initial bisphenol and phenol is $0.1: 0,9$, the repetitive ring of novolac oligomer has the following structure (Fig.4):<smiles>O=C1O[C]c2ccccc2C1C1CCCCC1</smiles>

Fig.4

The conditions of synthesis are given in Table 4: 
Table 4. Properties of the complex oligomers obtained on the basis of card-type bisphenols, phenol and formaldehyde, and conditions of their synthesis in melt in the presence of an acid catalyst*

\begin{tabular}{|c|c|c|c|c|c|c|}
\hline 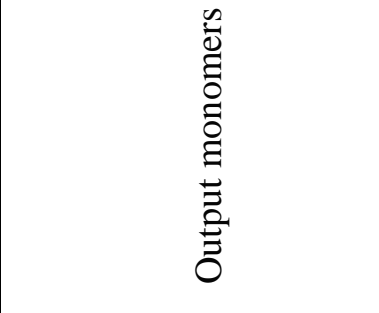 & 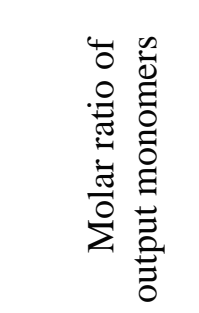 & 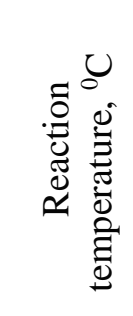 & 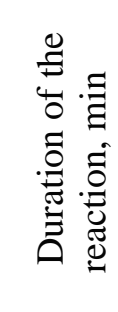 & 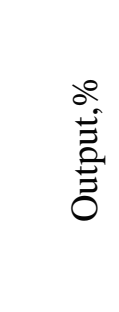 & 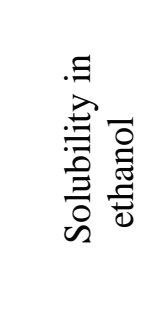 & 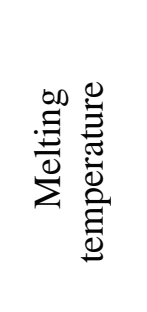 \\
\hline $\begin{array}{l}\text { Phenolphthalein:ph } \\
\text { enol: formaldehyde }\end{array}$ & $0.1: 0.9: 1$ & 100 & 30 & 81 & soluble & $160-180$ \\
\hline $\begin{array}{c}\text { 1.1-bis(4- } \beta \text { - } \\
\text { oxiphenyl) } \\
\begin{array}{c}\text { cyclohexane:phenol:fo } \\
\text { rmaldehyde }\end{array} \\
\end{array}$ & $\begin{array}{l}0.1: 0.9: \\
0.9\end{array}$ & 80 & 10 & 88.78 & soluble & $90-100$ \\
\hline $\begin{array}{c}\text { 2.2-bis(4- } \beta- \\
\text { oxiphenyl) } \\
\text { norborneylidene:phen } \\
\text { ol:formaldehyde }\end{array}$ & $\begin{array}{l}0.1: 0.9: \\
0.9\end{array}$ & 80 & 10 & 88.85 & soluble & $105-110$ \\
\hline $\begin{array}{c}\text { 5.5-bis(4- } \beta- \\
\text { oxiphenyl) hexahydro- } \\
\text { 4,7-methyleneindane- } \\
\text { 5ylidene:phenol:forma } \\
\text { ldehyde }\end{array}$ & $\begin{array}{l}0.1: 0.9: \\
0.9\end{array}$ & 80 & 10 & 93.56 & soluble & $115-120$ \\
\hline $\begin{array}{c}\text { 2.2-bis(4- } \beta \text { - } \\
\text { oxiphenyl) decahydro- } \\
\text { 1,4,5,8- } \\
\text { dimethylenenaphthyl- } \\
\text { idene:phenol:formalde } \\
\text { hyde }\end{array}$ & $\begin{array}{l}0.1: 0.9: \\
0.9\end{array}$ & 80 & 10 & 87.28 & soluble & $120-125$ \\
\hline $\begin{array}{c}\text { 2.2-bis(4- } \beta \text { - } \\
\text { oxiphenyl) } \\
\text { adamantane:phenol:for } \\
\text { maldehyde }\end{array}$ & $\begin{array}{l}0.1: 0.9: \\
0.9\end{array}$ & 80 & 10 & 75.46 & insoluble & 130-135 \\
\hline
\end{tabular}

\section{* Catalyst $-15 \% \mathrm{HCl}$ in relation to phenol}

Introduction of card-type bisphenols into the composition of phenol-formaldehyde oligomers increased the softening temperature of co-oligomers from $70{ }^{0} \mathrm{C}$ to $90-180{ }^{\circ} \mathrm{C}$. The oligomers containing phthalide card-type groups had the highest softening temperature.

If we compare the contribution of card-type structure groups to the increase in the softening temperature, we can arrange them in the following row (Fig.5):

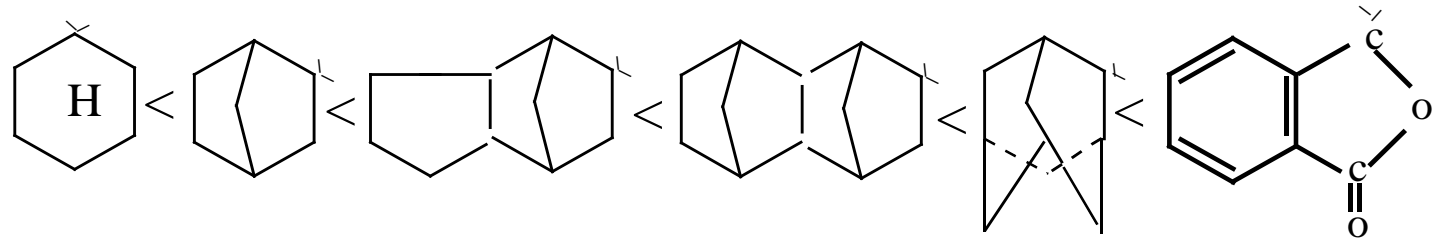

Fig.5

The obtained oligomers dissolve in acetone, cyclohexane, dimethylformamide, tricresol, etc. They partially dissolve in ethanol, except the oligomers containing cyclohexane and norbornane cyclic groups, which are characterized by very good solubility in spirit.

Under the influence of hexamethylenetetraamide at $180-200^{\circ} \mathrm{C}$ the oligomers undergo hardening and transform into spatially-structured resite. 


\section{Conclusions.}

1. A new continuous method of production of novolac-type oligomers by interaction of phenol with paraform in the melt in the presence of an acid catalyst was developed. To establish the optimal conditions of the reaction, some kinetic regularities of the process were investigated. It is shown that the reaction is of the second order.

2. The optimal conditions for formation of the oligomer are the following: temperature -100 $120{ }^{\circ} \mathrm{C}$; duration of the reaction $-10 \mathrm{~min}$; phenolic component: formaldehyde molar ratio - 1.15:10; amount of the catalyst $-1 \%$ in relation to the phenolic component.

3. The introduction of card-type bisphenols to increase the heat resistance caused an increase in the softening temperature of co-oligomers from $70{ }^{\circ} \mathrm{C}$ to $90-180^{\circ} \mathrm{C}$.

4. If we compare the contribution of groups having card-type structure with the increase in the softening temperature, we can arrange them in the following row, which is given on Fig.2.

\section{REFERENCES}

1. Petrov G.S., Rutkovskiy B.N.., Losev I.P. Technology of synthetic resins and plastic masses. M. L., Goschimizdat, 1946, pp.52-54.

2. Mayer H., A method for production of shellac type resinous product from solution of phenol and formaldehyde. German Pat. \# 172877, 1906.02.07, Application 1902.12.04.

3. Bakhman A., Muller K. Phenoplasts, M. Chemistry, 1978, pp. 1-16.

4. Shorigina N.V., Popova T.A., Pyren-phenol-formaldehyde resins, plastics, 1967, 9, pp. 19-21.

5. Sergeev V.A., et.al. Thermoreactive copolymers of phenols and complex structure phenols with formaldehyde. High molecular weight cjmpounds, A 10 (1068, 10, p.2304.

6. Waker J. F. Formaldehyde. Publishing house Chemistry, M. 1957, p. 431.

7. Nelson J.D. [General Electrik Co.]. One stage process for obtaining of phenolic resins

8. from polymethylenepolyphenols, phenol and formaldehyde. USA Pat. 3445431(1969). Cl.26051 (08g), Application 15.08.68, published 20.05.69, RJChim 1970, 13C384p.

9. Megson N.J.I. Phenolic Resin Chemistry. -New York, Academic Press, 1958, pp.40-45.

10. Technology of plastics (edited by V.V. Korshak. -Moscow, Chemistry, 1985, 251 p.

11. A.M. Toroptseva, K.V. Belgorodskaya V.M. Bondarenko. Laboratory practice in chemistry and technology of high-molecularcjmpounds. - Leningrad, Chemistry, 1972, $218 \mathrm{p}$

12. Korshak V.V. Progress of polymer chemistry, M. Nauka, 1965.

13. Atsushi Izumi, Yasuyuki Shudo, Katsumi Hagita, Mitsuhiro Shibayama,Molecular Dynamics Simulations of Cross-Linked Phenolic Resins Using a United-Atom Model, Macromolecular Theory and Simulations 2018 53, 1700103

14. Shaiber bI. Chemistry and technology of synthetic resins. M-L., Goschemizdat, 1949, p. 347.

15. Kunwoo Lee ${ }^{a}$ Kangro Yoon a Jinhwan Kim a Jinyoung Bae a Jaeho Yang banghyun Hong, Effect of novolac phenol and oligomeric aryl phosphate mixtures on flame retardance enhancement of ABS, Polymer Degradation and Stability, Elsevier Science Ltd., https://www.sciencedirect.com , Volume 81, Issue 1, 2003, Pages 173-179.

16. Cheng Bian, Shujuan Wang, Yuhong Liu, Kehe Su, and Xinli Jing, Role of Nonbond Interactions in the Glass Transition of Novolac-Type Phenolic Resin: A Molecular Dynamics Study, ,Industrial \& Engineering Chemistry Research 201655 (35), 9440-9451

17. Georgieva, M. P., Mateva, R. P., Novakov, P. H. and Glavchev, I. K. 'Laboratory Experiments in Chemistry and Technology of Polymers', Technika, Sofia, Bulgaria, 1984, p. 191 I 1

18. J. S. Xiaofeng, H. P. Yi, Z. L. Mo,Condensation Reaction of 1,2,3,4-Tetrahydro-1,10-phenanthroline and Formaldehyde: Synthesis and Crystal Structures of Bis(1,2,3,4-tetrahydro-1,10-phenanthroline-6yl)methane and Its p-Toluenesulfonate Salt, S. P. Chen,Crystallography Reports 201762 (7), 1128-1134

19. Komarova L.I., Lokshin B.V., Sergeev V.A., Korshak V.V. Study of IR absorption spectra of phenolformaldehyde resins in the process of hardening and thermal destruction. In Applied Spectroscopy, materials of the XIV meeting, Moscow, January 28-February 2, 1965. M.Nauka, 1969, v.2., pp. 100-104.

20. Korshak V.V., Komarova L.I., Sergeev V.A., Lokshin B.V., Doroshenko Y.E. Investigation of IR absorbtion spectra of polymers on the basis of Bisphenols and formaldehyde in the process of their hardening and thermal destruction. Journal of Applied Spectroscopy. 1967, v.7, issue 4, pp.611-614.

21. Jason S. Moore*, Michael P. Landoll, and William W. Fan, Novolac Phenol-Formaldehyde Oligomerization Kinetics Analysis, Copyright (c) 2015 American Chemical Society,Ind. Eng. Chem. Res., 2015, 54 (51), pp 12757-12762, https://pubs.acs.org/doi/full/10.1021/acs.iecr.5b03756

22. Abnerova S.V. Investigation in the sphere of phenolformaldehyde type polymers on the basis of bisphenols with cycloparaffinic groups. Candidate's dissertation, Tbilisi, 1979, pp.22-32.

23. Molodinashvili.Z.F., Obtaining of phenol-formaldehyde oligomers and polymeric compositions in alloys, plastic materials on their basis, obtaining and properties. Dissertation for the degree of candidate of chemical science. Iv. Javakhishvili Tbilisi State University. 02.00 .06 - Chemistry of high-molecular compounds, Tbilisi, 2006, pp.44-56. 